\title{
TRADITIONS AND INNOVATIONS IN THE TRAINING ON "GEOGRAPHY OF COUNTRIES" IN THE SECONDARY BULGARIAN SCHOOL
}

\author{
Stella DERMENDZHIEVA \\ Department of Geography, „St. Cyril and St. Methodius” University of Veliko Tarnovo \\ stela.dermendzhieva@mail.bg \\ Tamara DRAGANOVA \\ Department of Geography, „St. Cyril and St. Methodius” University of Veliko Tarnovo \\ tamara draganova@mail.bg
}

\begin{abstract}
The geography training of the countries in the secondary school opens a new page of the regulatory framework for the 2018/2019 school year, in which a new curriculum will be constructed. Knowledge of the geographical regions, their countries and typical representative countries for a given region, the tracking of the complex influence of natural, historical, economic, demographic and political factors for the formation of the regions, their differentiation in Europe, Asia, America, Africa, Australia and Oceania, and assessing the importance of countries by region for forecasting the development of geographic regions is one of the current and modern geographical tendency - regionalization.

The transition from the traditional accumulation of knowledge to the problematic development of the learning process aims at revealing and discussing the territorial manifestation of the problems of each region and country or group of countries, with outlining the specific problems and explaining the causes of the emergence.

A system idea is built for an action approach at several levels of formation: general theoretical idea; structure; functions. In the theoretical and practical aspects are search for variants for construction models, techniques and technologies for the control of studying geography on countries.

The aim of the current research is formation of conceptual and situational analysis of the training for the countries on the new curriculum, to identify and provide acquired educational traditions to regional geography under the new conditions, as well as revealing and presenting of the innovations in the new curriculum for the 9th grade covering the study of the countries.

The methods of the research are conceptual analysis, situational analysis, comparative analysis, synthesis and summarization, interpretation method, causal investigation, etc.

The main results are: a sharp contrast in the number and content of the active verbs on one level - curriculum; the new curriculum contains only the main aim; the structural model of the curriculum impersonates with a specific, which is non - traditional for the Bulgarian geographic education as a tradition in the curriculum preparation till now; Learning content by themes is not defined by cores, standards, and themes, but is composed by themes, competences such as expected training results and new concepts; traditionally, there is the requirement of an algorithm/rule in the curriculum for region and country characterization; the innovative moment in country characterization is given by specific examples of countries characterization - 10 countries are proposed for study; changing the learning and communication environment in which environment should be given more space for the interaction; Geography training of countries in the first level of high school is configured to support the knowledges, skills and attitudes of V, VI and VII grade and other.
\end{abstract}

Keywords: curriculum, geography school education, Geography of countries, traditions and innovations.

\section{Resumo}

Ao nível do ensino médio, no ano letivo de 2018/2019, abre-se um novo marco no que diz respeito ao ensino da Geografia, já que se configurou um novo currículo. O conhecimento das regiões geográficas dos respetivos países a que acresce o estudo dos países representativos de uma determinada região, a compreensão da influência complexa de fatores naturais, históricos, económicos, demográficos e políticos para a formação das 
regiões e sua diferenciação na Europa, Ásia, América, África, Austrália e Oceânia, são imprescindíveis, pois só avaliando a importância dos países por região e se conseguirá fazer a previsão do desenvolvimento das regiões geográficas, uma das tendências geográficas atual e moderna - a regionalização.

A transição da tradicional acumulação de conhecimento para um processo de aprendizagem das problemáticas, tem como objetivo revelar e discutir a manifestação territorial dos problemas de cada região e país, ou de um grupo de países, delineando as debilidades específicas e explicando as causas do seu surgimento.

Uma ideia de sistema é construída para uma abordagem ativa em vários níveis de formação: ideia teórica geral; estrutura; funções. Nos aspetos teóricos e práticos, buscam-se variantes para modelos de construção, técnicas e tecnologias para o controle do estudo da geografia nos países.

Palavras-chave: currículo, educação escolar de geografia, Geografia de países, tradições e inovações.

\section{Regional projections of the new curriculum - Educational reform and school geography}

„Knowledge by itself is power"

Francis Bacon

Geography and economics training in the Bulgarian school is an important aspect of understanding our place in the world as well and how people interact with each other and their environment. School education is a bearer of knowledge and strength with a specific educational and social shade that creates the future of every nation. School geographic education increases the tolerance and cultural understanding, interaction and interdependence, equality and fairness at different levels - locally, regionally and globally. The educational vector for students is aimed at expansion the opportunity to develop socio-economic, socio-cultural and environmental values, to continue the formation of rational models of behavior in geographic space through geographical training to create people with a broad geographic culture for the political and socio-economical organization of society, the regions in the world and the countries in them.

Knowledge of the geographical regions, their countries and typical representative countries for a given region, the tracking of the complex influence of natural, historical, economic, demographic and political factors for the formation of the regions, their differentiation in Europe, Asia, America, Africa, Australia and Oceania, and assessing the importance of countries by region for forecasting the development of geographic regions is one of the current and modern geographical tendency regionalization. The regional projection of the new curriculum is expanded to geographically identifying and naming the world's regions, characterizing regions and selected countries as a rule with the help of information technology. Through the training for countries are applied and other modern geographic trends - economics, sociology, humanization, ecology and etc. The learning content of the training in the Bulgarian school on geography of the countries reflects the current trends in the development of the geography.

The geography training of the countries in the secondary school opens a new page of the regulatory framework for the $2018 / 2019$ school year, in which a new curriculum is constructed. 


\section{Traditions and Innovations in the training on "Geography of countries" under a regulatory framework}

According to the framework learning plan, the geography training in the IX-th grade has an annual workload of 36 or 72 teaching hours and the regional part is localized in both cases at the end of the training as the last section. The new realities and normative changes, as well as the introduction of a new law for education, teaching plans and curricula, generalize a new learning environment, objects and subjects, processes and phenomena.

The training in geography of the countries in IX-th grade on the new curriculum, which is a compulsory operational document, shows the traditions and innovations in the training for the countries.

\subsection{Structural model of the curriculum}

The structural model of the curriculum impersonates with a specific, which is non - traditional for the Bulgarian geographic education as a tradition in the curriculum preparation till now. The IX-th grade curriculum is the winner of an innovative structure reworked in line with the European reference educational framework and the requirements of international documents covering the school geography education and the geography training. Traditional segments of the curriculum are the main aim, the learning content of topics, competencies such as expected training results and new concepts; specific methods and forms for assessing students' achievements; context and activities; opportunities for interdisciplinary links. Innovative segments of the new curriculum are: expected training results to achieve general education preparation at the end of the class; the recommended percentage distribution of compulsory school hours (further details); activities to acquire key competences; interdisciplinary links on key competences.

Part of the traditional segments also present in the new curriculum with an updated reading and a new evolved form transformed from the requirements of the European reference educational framework and the international operative documents (European Communities, 2008).

Traditionally, in the geographic curricula of the geography at general curriculum present the main purpose of the training, while the purposes of geography and economics training are presented separately. The new curriculum contains only the main aim, which is "aimed at acquiring key competences by mastering the knowledges, skills and attitudes related to the political and socio economic organization of society, the regions of the world and the countries in them". (UCHEBNA PROGRAMA, 2017, p. 1).

\subsection{The State Educational Standard and Curriculum}

An innovative segment of the new curriculum on geography and economy is the content of the expected training results to achieve general education preparation at the end of the class. The State Educational Standard (DOS) in geography and economics for the middle (secondary) stage of the first 
high school level was fully transferred and transformed into the curriculum for the IX-th grade in terms of training for countries in the section Geography of continents and countries (Figure 1).

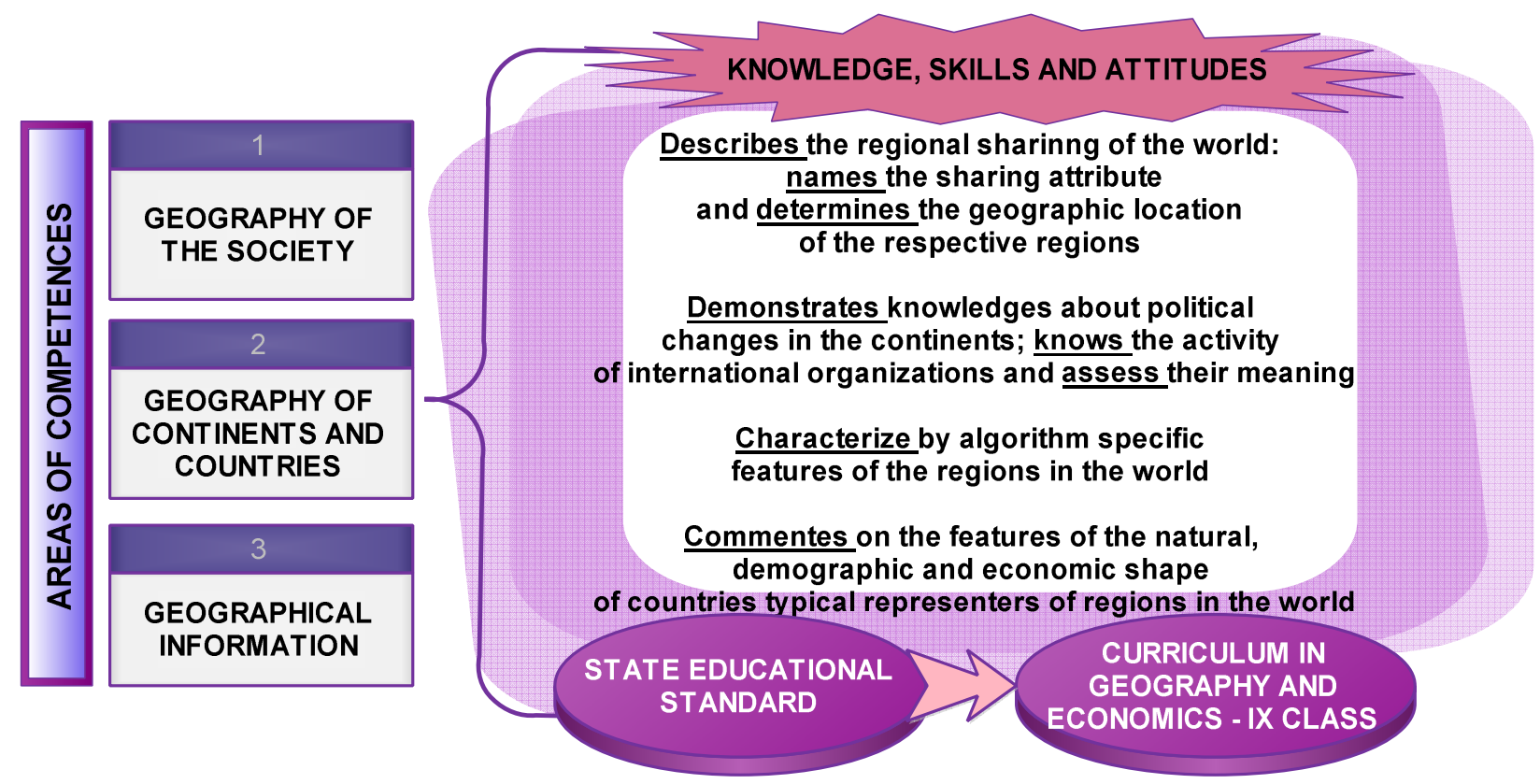

Figure 1 - Transfer of the expected training results to achieve the general education preparation at the end of the class by DOS and curriculum

Source: Uchebna programa po geografiya I ikonomika za IX klas (2017), Naredba № 5 ot 30.11 .2015 g. za obshtoobrazovatelnata podgotovka, (2015)

The presence of the expected results by state standard and curriculum in one normative document is an opportunity to reveal the peculiarities of the educational process in geography and to increase the quality and effectiveness of the training, to compare and juxtapose the minimum requirements in standard and curriculum, to follow the educational strategy for development of secondary education.

An interesting moment of transferring the expected results for knowledges, skills and attitudes from the DOS and their presence in the theme geography of the continents and countries in the curriculum is to the competencies as the expected result of the training on the learning content in the curriculum. We identify a sharp contrast in the number and content of the active verbs on one level curriculum. At the end of the training, 4 expected results are obtained, but with the presence of 8 active verbs for the realization of the results. On theme 2, three active verbs were applied to the total of 4 expected results, with only two are carry of the expected results at the end of the class - named and characterized. Strongly reduced is the proposed for the last high school class of the compulsory preparation on geography a poly - variety of active verbs for the achievement of the expected results on regional geography which do not have its methodical - didactical justification (Figure 2). 


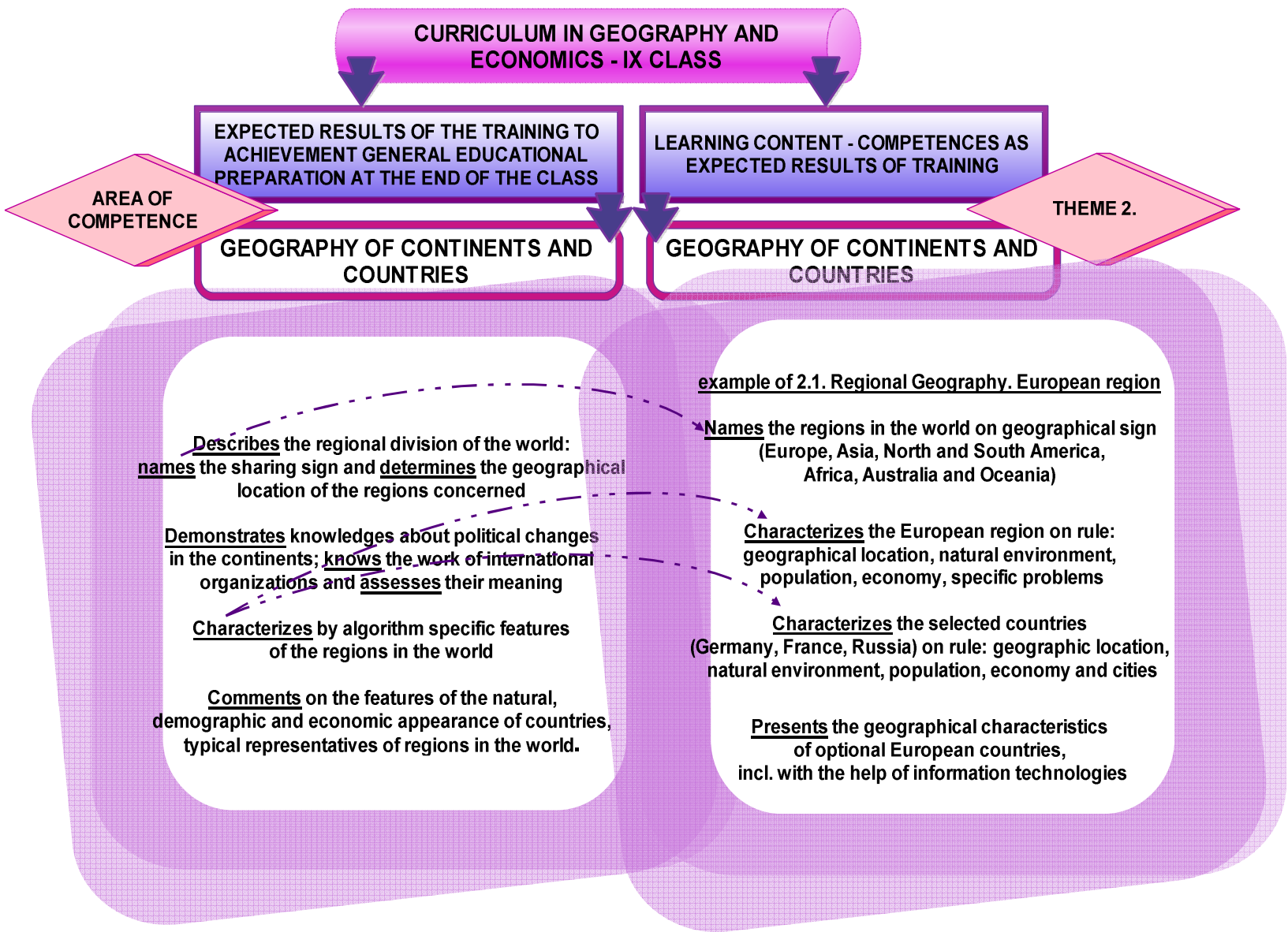

Figure 2 - Transforming the expected results at the end of the class and by the theme from learning content of the curriculum

Source: Uchebna programa po geografiya I ikonomika za IX klas (2017)

\subsection{Curriculum of Geography and economy 9th grade}

Learning content by themes is not defined by cores, standards, and themes, but is composed by themes, competences such as expected training results and new concepts. As an innovative moment in the curriculum in learning countries, we define the learning content, which is decomposed into three components - topics, competences such as expected training results and new concepts.

Of total two themes in the curricula, the second covers regional geography with the name Geography of continents and countries, which includes two subtopics. The title of the main theme differs from the previous one in the curriculum (until 2018) - Geographical regions in the world and countries in them, but it is preserved and with presence of the main aim of presenting the new curriculum. The tradition of the fourth period in the development of school geography after 1989 for the study of regional geography on continents and countries, and not of regions and countries that have a radically different contentious - spatial idea and a trans - territorial foreshortening of learning, has been preserved. 
The themes in the new curricula are reduced to 2 with extremely overlapping of competencies as expected training results for the two subtopics - limited to the three active verbs - naming, characterizing and presenting (DRAGANOVA, 2018, p. 33). For comparison, in the previous curriculum there are a total of 16 active verbs on the five core themes - Geographic regions of the world and countries in them. The themes in the new curriculum, compared to the previous curriculum in which they are 5 , are extremely reduced in number but with a regional - territorial and inductive deductive approach of presence.

By competences as the expected training results for the two sub - topics is defined imperative approach of studying the countries by regions - regional - territorial and system - typological approach. There is an obvious preserved educational tradition of school geographic education in the approaches of studying the countries in the new realities.

The innovative moment in country characterization is given by specific examples of countries characterization - 10 countries are proposed for study: Europe - Germany, France and Russia; Asia Japan, China, India; North and South America - USA and Brazil; Africa - the Republic of South Africa; Australia and Oceania - Australian Union (UCHEBNA PROGRAMA, 2017, p. 6). The educational tradition of studying a selected country or countries as typical representatives of the studied region is preserved.

Traditionally, there is the requirement of an algorithm/rule in the curriculum for region and country characterization. Unlike the previous curriculum, which does not contain the algorithm itself, the new program has innovative changed the name - rule and contains clearly sequenced steps to characterize region and country. The two rules differ in the last step of a total of 5 steps characterization of the specific problems of the region and characterization of the cities (DRAGANOVA, T., 2018, pp. 32-33). Both rules for region and country characterization are traditional geographic algorithms, which are also preserved in the new educational realities of school geography.

The curriculum specificity is the third component of the curriculum - new concepts in which we identify 3 new concepts that are not directly relevant to country learning but are responsive to training for regional organizations that is part of the same theme 2, in the second subtheme. The presence of concepts such as number and type, content and separation on the two themes of the curriculum is a necessity because the concepts are one of the most important components of the theoretical - content side of geographic knowledge. As a result of their reasoned presence in the curriculum, they may lead to an increase in the scientific - theoretical level of geography training. The minimum number of concepts presented in the curriculum is not substantiated, and they are considered as abbreviations of international organizations for the full coverage of competences as the expected results of the training on sub - theme 2.

An innovative segment of the curriculum is the presentation of the recommended percentage distribution of compulsory school hours and further details of the school subject geography and economics. The recommended framework for the allocation the school hours for the school year at the same time provides teacher's didactic freedom to achieve the expected curriculum results, geographic literacy and culture formation, and behavioral models in IX-th grade training. In the context of the percentage distribution of learning countries, more attention is paid to the lessons of new knowledges, 
but minimum of other types of lessons, with some of them are not even having a presence on theme 2 in this percentage distribution.

The specific methods and forms of assessing student achievements, de facto, is a traditionally present segment in curricula, but de jure with radically different content in the new geography curricula. An innovative moment is the presence of a ratio in the formation of a term and an annual assessment, which is tabulated presented as a percentage between current assessments, evaluations from control work and estimates from other participations. Innovative are the forms of work and assessment - group work, housework and etc., as well as the traditional - oral and written tests, work in class and etc.

The combined application of traditional and interactive methods is part of the overall conceptual framework of the curriculum, with a strong presence of interactive methods in learning content, such as expected learning results, key competency acquisition activities, and interdisciplinary links. Innovativeness has been brought to the new realities with the application of interactive methods and training techniques such as research method, problem and project method, methods of analysis intellectual map and others.

An innovative moment in the curriculum is its integration with the European reference educational framework (European Communities, 2008) and the requirements for the geography training of the international documents. In an innovative European context, there are also extensive activities for acquire 6 of the key competences. Activities are configured on key competencies through B. Bloom's active taxonomy verbs. All the activities described are applicable in countries training and provoke interaction, application of skills and habits and all activities are aimed to the direct use of geographic knowledges in the practice. An example of such activities are:

$\rightarrow$ "generating and interpretation of geographic and economic information from various sources - work with documents, work with statistical materials, compound a plan - conspectus and etc .

$\rightarrow$ using electronic based information sources for searching, collecting, interpreting, presenting and exchanging specific geographic and economic information;

$\rightarrow$ using information technologies to create and present products from a specific task;

$\rightarrow$ expressing an opinion and commenting on geographic questions, study/science popular/documentary films;

$\rightarrow$ discussing geographic problems and offering ways to solve them, as well as solving case studies and argumentation for solutions;

$\rightarrow$ working with all elements of the textbook, working in a team;

$\rightarrow$ assessing the meaning of objects, processes, phenomena;

$\rightarrow$ comparing, differentiating, referencing, grouping, classifying, characterizing, analyzing, commenting on geographic objects, processes and phenomena;

$\rightarrow$ making generalized conclusions;

$\rightarrow$ reading a geographic map and analyzing different types of graphics, diagrams and other graphical images, and drawing schemes, tables, maps, etc., as well as identifying and locating geographic objects on the map." (UCHEBNA PROGRAMA, 2017, p. 8) 
In traditional and innovative plan presence has interdisciplinary links but with a different number, conceptual - idea and competency basis, in line with the European reference educational framework, the Law for pre - school and school education (ZPUO), the DOS and the learning framework plans and curricula. As an innovative moment of view, the interdisciplinary connections between the nine key competences, with specific examples and the name of the school subject matter of general education preparation, are outlined (ZAKON, 2015). Of the 20 general education school subjects under the ZPUO and Regulation No. 5/30.11.2015, outside of the school subject of geography and economics, the horizontal dispersion is directed to 11 school subjects for 1 school subject (history) from the curriculum until 2018 (Figure 3).

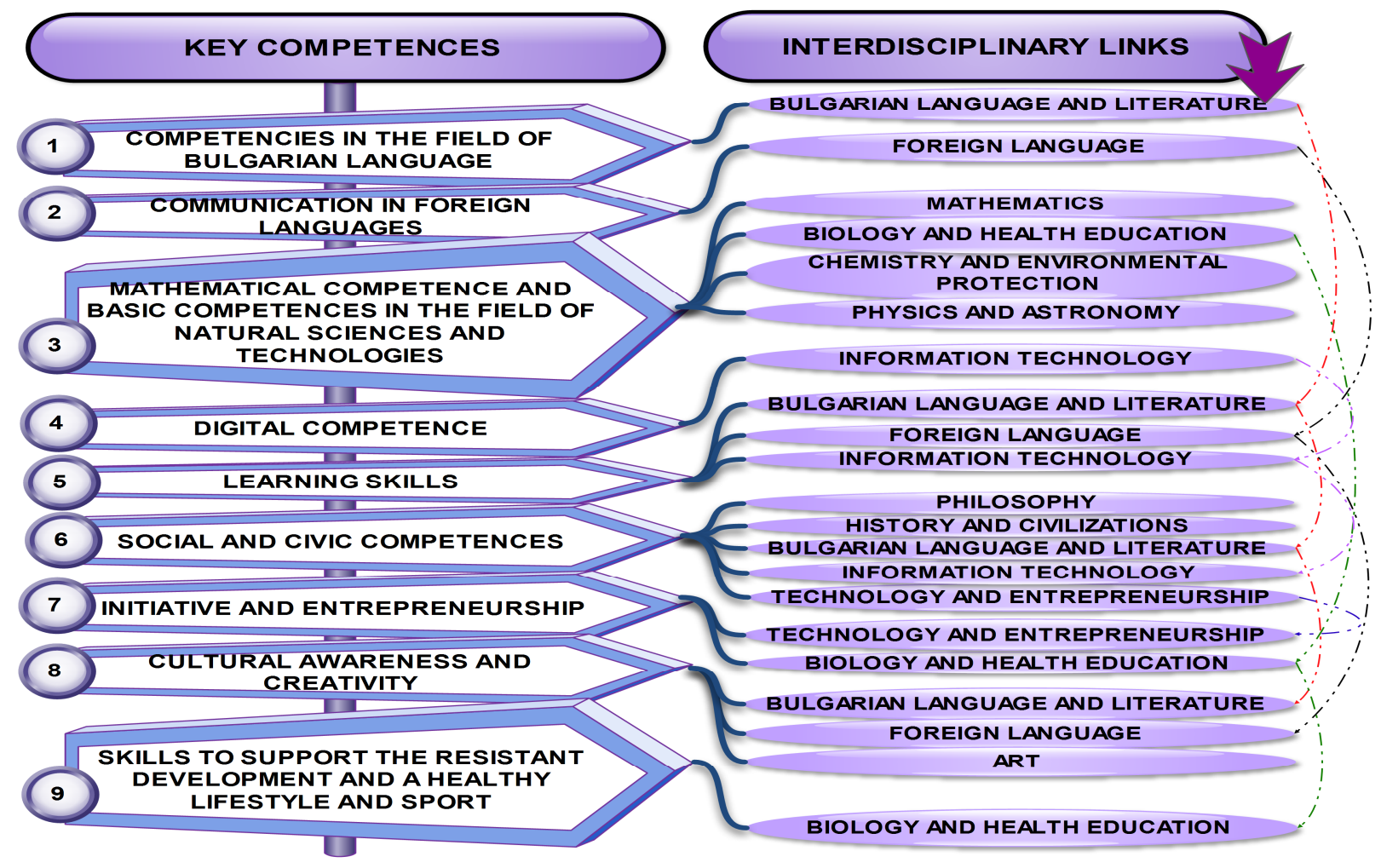

Figure 3 - Graphic organizer for the horizontal links on key competences by curriculum

Source: Uchebna programa po geografiya I ikonomika za IX klas (2017)

\subsection{The horizontal (interdisciplinary) links in Curriculum}

The horizontal links outlined in the curriculum are based on 9 key competences, with the repeatability of some of the school subjects but with a different content and behavioral aspect in the formulation, specification and operationalization by taxonomy of the active verbs and activities. The school subject Bulgarian language and literature is applied to key competences 1, 5, 6 and 8, with a repeatability of 5 times in total, with specific activities and activity - uses, expresses, selects, compares, formulates, enriches, develops, assesses, listens, forms. 
The foreign language is based on key competences 2, 5 and 8 as an opportunity to use knowledges and develop a "foreign language culture in the process of exploring additional geographic information" (UCHEBNA PROGRAMA, 2017, p. 9) as well as expanding and deepening the intercultural competences, and the formation of single concepts for cultural and historical landmarks in different regions. Applicability is relevant and present in characterizing a selected country as a rule: geographical location, natural environment, population, economy and cities.

The school subject Biology and health education is referenced as a horizontal connection on key competencies 3, 7 and 9. The construction of horizontal linkage is consolidated on deepening the knowledges about the ecological factor and the enrichment of the ecological culture in the process of realizing the connections between nature - society - economic activity, as well as the necessity to preserve and support the environmental activities of the different territorial - spatial units - continent, region, country, group of countries.

The Information technology school subject is applied on key competences 4, 5 and 6, with a total repeatability of 4 times, with a defined explicit presence in the curriculum for theme 2 and the two sub - themes in presenting the geographic characteristics of countries from a selected region by optional using the information technologies.

The school subject of Technology and entrepreneurship is related to key competences 6 and 7 , which horizontally links and develops "teamwork skills, solving and rationally argumentation of case studies related to the development and localization of economic activity" (UCHEBNA PROGRAMA, 2017 , p. 9, p. 10), as well as with economic concepts and basic principles of economic integration in the study of the countries.

The following subjects have a single presence in the curriculum, but not in the teaching process of geography, with an example of a horizontal connection: Mathematics, Chemistry and environmental protection, Physics and astronomy, Philosophy, History and civilization, and Art.

All indicated interdisciplinary links outlined in the curriculum are explicitly and implicitly relevant to the content context of the training for the countries. The collaboration of the horizontal links in the countries' geography training is encoded by the aims and principles of education through the DOS and the curricula, and their methodical - didactic spiraling and absorption of the systematic geographic knowledge in the Bulgarian school, with a clear synchronization of the processes of training, upbringing and socialization.

\subsection{The vertical (intradisciplinary) links in Curriculum}

Geography training of countries in the first level of high school is configured to support the knowledges, skills and attitudes of V, VI and VII grade which are expanded and deepened by vertical links for the theme Geography of the continents and the countries. Traditionally, the mixed curriculum model has been preserved and saved in the construction of the curriculum. The tradition of stepwise formation of geographic culture, „skills building, the development of cognitive abilities and active values attitudes" has been preserved, with the unchanging presence in the normative framework of 
the complex and systemic approach (DERMENDZHIEVA, Stela, SABEVA, Petya, DIMITROVA, Boyanka, 2010).

An innovative training line, supported by the new normative basis, is aimed at turning the theory into a various practical dimensions. The transition from the traditional accumulation of knowledges to the problematic development of the learning process aims at revealing and discussing the territorial manifestation of the problems of each region and country or group of countries, outlining the specific problems and explaining the reasons of the emergence. The change encompasses the didactic flatness of transition and strengthening the productivity in geography training of the countries.

An innovative moment, as a social order of the post industrial society, is education, which develops in parallel with the development and application of information and communication technologies (ICT) in the learning process. In the training for the countries is explicitly present in information technologies in theme 2 of the curriculum when presenting the geographical characteristics of countries in a given region. By applying ICT in training for the countries, achieves the development and improvement of ICT skills and, on the other hand, the assimilation of skills for use and application of ICT in training, daily life and realization of the policy for learning throughout life and access to information.

In the whole learning process, in the study of the countries, the students from the $\mathrm{V}$-th grade to the IX-th grade assimilate the basis of the systematic geographic knowledge based on the conceptual idea of the final training results, which includes theoretical (theories, laws, principles, basic concepts) and methodological (way of activity) knowledges and skills of the curriculum before 2018. In the new curriculum and normative changes are proposed in the new conceptual framework which is more advanced, comprehensive and with clearly defined components of the content - procedural aspects.

The basis of systematic geographic knowledge includes two basic components of the geographic competence - meaningful and procedural (Figure 4). Each of them includes a system of knowledges, skills and attitudes that are decomposed from their side into elements that are bearers of the objective truth in geographic science and the scientific knowledge imported to the school geography. The educational perception of the synthesis of geographic knowledges, skills and habits, as well as models of behavior are also in the basis of training for countries with aim studying the geographical reality and personal perception of students and to interpret the reality and spatial organization of the society.

In order to reach the perception of the geographical environment and the formation of objective ideas it is important to form knowledges about the system of facts and volume of geographic nomenclature which will discover the possibility of following development of the geographical culture. Subject knowledges of geographical facts and geographic nomenclature are a means of clarifying the scientific hypotheses and theories, of discovering the causative - investigation connections and laws through applying specialized geographic terminology - or knowing and using geographic concepts. Empirical and theoretical geographic knowledges are the substantive and basic aspect of the geographic competence of modern person who can make an objective and up-to-date interpretation and assessment of the perception. 

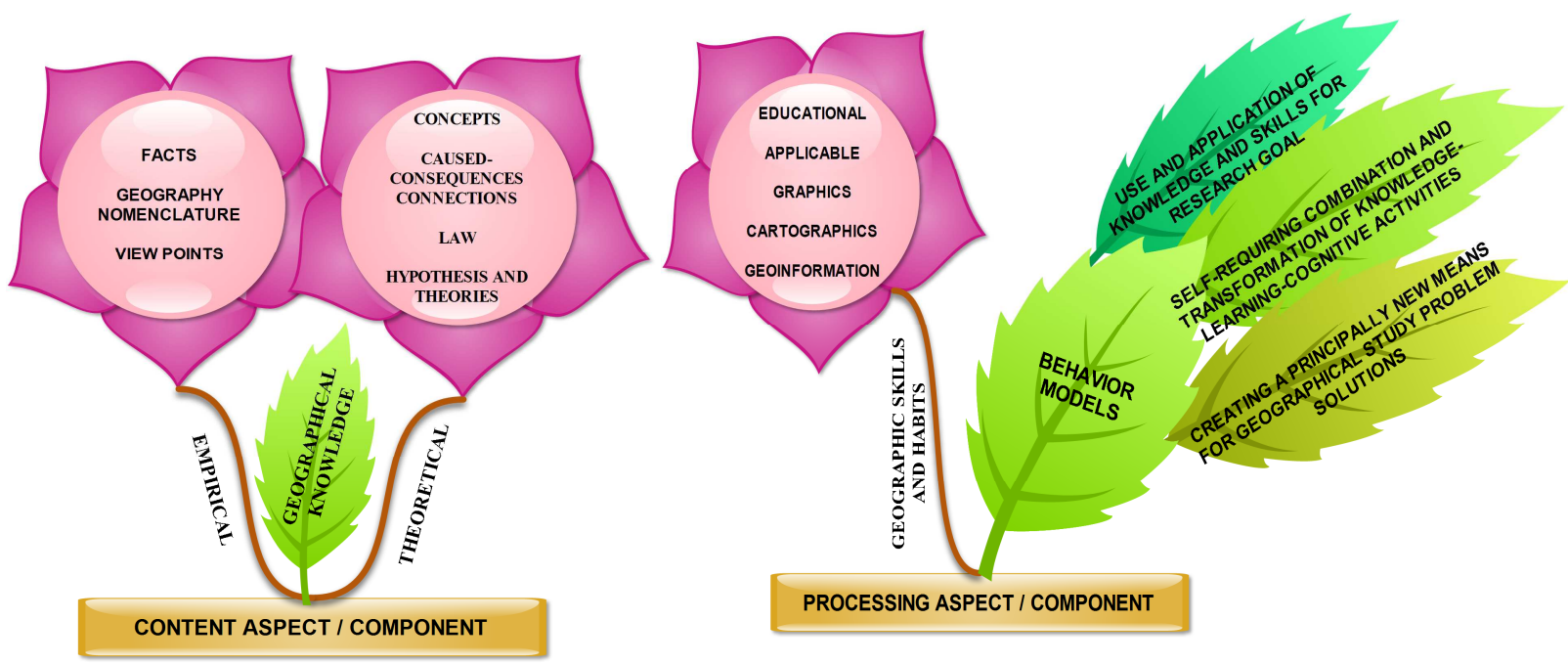

Figure 4 - Graphic organizer of content - procedural components of the geographic competence (Dermendzhieva, Stela, Sabeva Petya, 2018, p. 9).

Source: Dermendzhieva, Stela, Sabeva Petya. Kniga za uchitelya po geografiya i ikonomika. S., Prosveta, 2018.

The procedural aspect of geographic competence in terms of shaping models of behavior is a new innovative segment of the operational documents and a requirement for global trends in school geography training which is expression and reflection, continuation and natural expression of the unity of geographic knowledge, skills and habits for the geographic understanding of the world.

Innovative segment of training for countries with an advanced basis of traditional values is also the specific geography and economy aims for the first level high school of DOS in the area of the formation of values: interest in geographic knowledge; worldview of the system of nature - society economy; environmental protection; responsibility, tolerance and respect to the cultural diversity from the position of citizens of Bulgaria, Europe and the world (NAREDBA № 5, 2015, p. 73).

A new didactic foreshortening to DOC geography training is to continue the formation of skills by areas of competence - geographic information: receiving the information from different sources; interpretation and presenting the information; generating the geographic information. (NAREDBA № 5, 2015, p. 73).

\section{Conclusions}

Changing the learning and communicating environment, changing educational realities, under influence of the information society and its requirements, also leads to changes in the learning process of geography, changes in the school environment, relationships between students and teacher. Country training provokes interest in geographic science and knowledge, but the teacher is in the role of a collaborator, partner and facilitator in the learning process in which there is a redirection of the cognitive line from knowledge for... - to the knowledge of how... In modern training the roles of the two 
subjects changes, focusing on the interests, needs, motivation and activity of the students - the student is at the center of the training. (DERMENDZHIEVA, S. i dr., 2010, 54)

Enhancing the role of traditions and innovations in learning the countries in the new educational realities is aimed at changing the learning and communication environment in which environment should be given more space for the interaction. Essential for the efficiency of the learning process and the formation of an objective picture of the world is the organization of the training process using a variety of interactive methods, techniques and forms of work combined with traditional methods.

The penetration of modern techniques of teaching and learning, the penetration of modern ICT into the learning process, the globalization of the world, and the complication of human and social problems impose new, modern training methods.

\section{Bibliography}

Uchebna programa po geografiya I ikonomika za IX klas (2017). (obshtoobrazovatelna podgotovka po ramkovi uchebni planove).

DERMENDZHIEVA, S., SABEVA, P. (2018). Kniga za uchitelya po geografiya i ikonomika. Sofia, Prosveta.

Naredba № 5 ot 30.11 .2015 g. za obshtoobrazovatelnata podgotovka, (2015).

Zakon za preduchilishnoto i uchilishnoto obrazovanie, (2015).

DERMENDZHIEVA, S., P. SABEVA, B. DIMITROVA (2010). Geografiya i obrazovanie. Metodika na obuchenieto po geografiya, I chast. V. T., UI „Sv. sv. Kiril i Metodii”, 2010.

DRAGANOVA, T. (2018). Kontseptualen analiz na obuchenieto po geografiya na stranite $v$ novite realnosti po uchebna programa - IX klas, 41, pp. 30-35. 